\section{Interpretando direitos e incorporando novas agências: $o$ reconhecimento da Terra Indígena Las Casas, PA, e as perspectivas caiapó sobre esse} processo

Interpreting rights and incorporating new agencies: the recognition of the Las Casas Indigenous Land, PA and caiapó perspectives on this process

\author{
Juliana G. Melo*
}

Resumo: $\mathrm{O}$ artigo trata do processo de retomada e reconhecimento da Terra Indígena Las Casas, PA, de ocupação tradicional dos índios caiapó. O intuito é mostrar que os Caiapó interpretam esse evento, que é também jurídico e administrativo, a partir de suas próprias lógicas culturais, a ele incorporando novas agências e visões de mundo. Palavras-chave: Questões fundiárias indígenas; Etnologia indígena caiapó; Territorialidade.

Abstract: The article handles the process of taking up the recognition of the Las Casas Indigenous Land, PA, having been traditionally occupied by the Caiapó Indians. The aim is to show that the Caiapó interpret this event, which is also judicial and administrative, from the point of view of their own cultural logic and incorporate into it new agencies and world vision.

Key words: Indigenous land issues; Caiapó indigenous ethnology; Territoriality.

\section{Introdução}

Propõe-se a apresentar, a partir da realização de um trabalho de identificação e delimitação de uma "Terra Indígena", algumas das dinâmicas envolvidas no reconhecimento oficial de Terras Indígenas e discutir particularmente como
* Doutora pelo Programa de Pós-Graduação em Antropologia Social da Universidade de Brasília e Mestre em Antropologia Social pelo Programa de Pós-Graduação em Antropologia Social da Universidade Federal de Santa Catarina. Atualmente é professora Adjunta do Departamento de Antropologia da Universidade Federal de Natal, onde tem desenvolvido pesquisas no campo da Antropologia Jurídica. E-mail: juliana_melo2003@yahoo.com 
esses direitos são reinterpretados pelos indígenas. Trato especificamente do processo de reconhecimento legal da Terra Indígena Las Casas ${ }^{1}$, situada nos Municípios de Redenção, Pau d'Arco e Floresta do Araguaia (PA), ocupada por um coletivo de índios caiapó ${ }^{2}$. Ao discorrer sobre esse contexto, que é bastante peculiar, demonstro como a retomada desse território, para o grupo, implicou reinterpretações sobre aspectos centrais de sua organização social, como veremos adiante.

Diga-se, de passagem, que o conceito de território é polissêmico e multidimensional, possuindo um amplo leque de conotações (cf. Di Méo 2001, entre outros). No entanto a categoria "Terra Indígena" é jurídica e administrativa. Isto é, em um trabalho de identificação de uma Terra Indígena, de modo geral, o que se busca é reconhecer, através das narrativas indígenas e de extensa pesquisa documental e bibliográfica, elementos que comprovem a "tradicionalidade" de uma área indígena, conceito este que é também jurídico e administrativo.

Como consta no artigo 231, parágrafo $1^{\circ}$, da Constituição (BRASIL, 1988), [...] são terras tradicionalmente ocupadas pelos índios as por eles habitadas em caráter permanente, as utilizadas para suas atividades produtivas, as imprescindíveis à preservação dos recursos ambientais necessários a seu bem-estar e as necessárias a sua reprodução física e cultural, segundo seus usos, costumes e tradições.

Este artigo constitucional, por sua vez, é complementado por legislação infraconstitucional através do Decreto 1775/96 e Portaria 14/9633.

Ainda que o processo de regularização fundiária de uma Terra Indígena (TI) seja imensamente mais complexo, cabe ao coordenador de um Grupo de

\footnotetext{
${ }^{1}$ Esclareço que coordenei o Grupo Técnico (GT) de Identificação da Terra Indígena Las Casas, constituído pelas Portarias n. 992/PRES, de 6 dez. 2001 e n. 1051, de 19 dez. 2001. O trabalho realizado no âmbito de uma consultoria junto ao PNUD, por meio de um convênio estabelecido entre o Projeto Integrado de Proteção às Populações e Terras Indígenas da Amazônia Legal (PPTAL) e a Fundação Nacional do Índio (FUNAI) - consistiu na primeira etapa de regularização fundiária/reconhecimento legal desta Terra Indígena. Os trabalhos de campo tiveram duração aproximada de 45 dias. Concluída esta etapa, coube a elaboração do Relatório, que apresentou uma proposta de delimitação territorial da área, fundamentada em concepções que são próprias aos Caiapó, bem como em conceitos e categorias definidos pelo artigo 231 da Constituição Federal de 1988 e legislação infraconstitucional pertinente (Decreto 1775 e Portaria 14, ambos de 1996). O Relatório foi aprovado, publicado e a Terra Indígena Las Casas foi demarcada, reconhecida e, finalmente, homologada no ano de 2009. Os dados apresentados, em grande medida, são resultantes desse processo e fundamentam-se no Relatório Circunstanciado de Identificação e Delimitação da Terra Indígena Las Casas (Melo, 2002), bem como na dissertação A reinvenção da sociedade (Melo, 2004).

${ }^{2}$ Adoto a grafia Caiapó e não Kayapó, como se usa normalmente, pois compartilho da visão de alguns etnólogos, entre os quais Melatti, que consideram que o termo Kayapó não respeita a grafia correta do português, o que tem implicações de outras ordens.

${ }^{3}$ Noto que toda a legislação indigenista está disponível eletronicamente no site da Funai (www. funai.gov.br).
} 
Trabalho de Identificação e Delimitação, a partir da realização de um trabalho de campo marcado por situações bastante peculiares, promover uma espécie de "adequação" das narrativas indígenas sobre seu território, que são bastante fluidas e incorporam agências heterogêneas, para uma linguagem jurídica e administrativa que é, por sua própria natureza, hermética e passível de inúmeras "cristalizações", já que o direito opta pelo conceito de "verdade" ao de "interpretação" (cf. Kant de Lima, 2008).

Ao vivenciar essa experiência, que resultou em uma proposta de delimitação territorial que visava resolver uma situação de conflito fundiário estabelecido entre os Caiapó e a população regional, bem como em uma dissertação de mestrado (Melo, 2004), percebi que a perspectiva territorial indígena é muito mais ampla do que os conceitos e categorias jurídicos. De outro modo, entendi que, a despeito das dificuldades concernentes à realização de trabalhos como este - afinal, o tempo é exíguo e a situação em campo é geralmente tensa, já que é preciso mediar, muitas vezes, interesses opostos - creio que é possível construir boas interpretações nessas situações. Nesses contextos a presença de antropólogos é quase sempre bem vinda e, nesse sentido, é possível ter um acesso bastante amplo a vários domínios da vida social. Ademais, contar com o apoio das agências financiadoras contribuiu para a realização de uma pesquisa mais rica ${ }^{4}$. Esses aspectos, somados ao fato de que o conhecimento acadêmico de fato pode ajudar na garantia de direitos constitucionalmente assegurados, compensam, de certa forma, as dificuldades do trabalho.

Diante do exposto, o intuito desse artigo é tratar do processo de reconhecimento fundiário trazendo à tona a perspectiva de um grupo de índios caiapó que, naquele momento, tinham uma configuração social bastante singular - o que me permitiu tecer interpretações diferenciadas sobre esse grupo se levarmos em conta os referenciais teóricos mais recorrentes sobre os Caiapó (cf. Vidal, 1977; Turner, 1965; Lea, 1986; Verswijver, 1978, entre outros).

Aliás, cabe notar que o artigo não se propõe a dialogar mais densamente com a vasta bibliografia produzida sobre o grupo, ainda que o uso dessas teorias tenha sido extremante importante para perceber a singularidade e riqueza do contexto encontrado e, inclusive, para embasar teoricamente as hipóteses que elaboro sobre esse processo em seu sentido mais amplo. Tampouco tenho

\footnotetext{
${ }^{4} \mathrm{Eu}$, particularmente, pude fretar um avião e alugar um carro e com isto pude visitar e entrevistar pessoas que viveram em Las Casas, mas que hoje estão vivendo nas Terras Indígenas Caiapó e Xicrin do Rio Cateté. De outro modo, estive em cidades próximas da Terra Indígena, entrevistando pessoas importantes para entender a realidade de Las Casas, tendo viajado ainda para a cidade de Belém do Pará, onde passei uma semana estudando um arquivo extremamente rico do Serviço de Proteção aos Índios, datado de 1930-1970, onde encontrei informações valiosas.
} 
como proposta fazer uma extensa explanaçãosobre questões jurídicas que envolvem esse processo. O que busco, ainda que o objetivo seja audacioso, é trazer à tona a visão indígena, que é mais ampla que o conceito legal, ainda que precise estar, de certa forma, em consonância com tais aspectos legais para que a proposta de delimitação territorial seja oficialmente reconhecida pelo Estado Brasileiro.

Dessa forma, evocarei alguns eventos significativos para esse "coletivo" indígena, já que isso ajuda a reconstituir o processo de formação do grupo. Alguns episódios, como a "pacificação" ocorrida em Las Casas no ano de 1952 e o processo de retorno para a área na década de 1990, são especialmente reveladores quando permitem entender o processo de formação dessa comunidade, o que significa abordar a "filosofia" e formas de sociabilidade caiapó, tratando ainda da articulação entre concepções de mundo e práticas cotidianas. Afinal, essas ações são importantes para assegurar bases para uma vida em comum em um "lugar" especialmente significativo, conforme propuseram Overing e Passes (2000).

Ao analisar tais eventos, revelo que há também uma dimensão subjetiva que pode ser explorada nessas narrativas, pois os Caiapó, quando falam sobre esses eventos, parecem estar também relembrando suas próprias histórias de vida e experimentando os estados emotivos que essas lembranças suscitam. Através dessa ação, criam um senso particular de história, articulando suas trajetórias de vida à história do próprio território e da comunidade.

O intuito é também analisar as percepções indígenas sobre o espaço, pois compreendo que o movimento da vida social se dá justamente na "paisagem" O espaço, todavia, não é somente o palco sobre o qual reproduzem sua organização social, mas é locus de conhecimentos elementares e isto fica claro quando nos debruçamos sobre suas narrativas míticas e práticas sociais, reveladoras do próprio cosmos e de aspectos sutis da sociabilidade indígena. Outrossim, busco demonstrar como os grupos indígenas, de diversas formas, ampliam os dispositivos jurídicos, a eles incorporando novas agências e sua própria visão de mundo. Dar mais atenção para essas questões pode ser importante para pensar em até que sentido a noção de um território com "fronteiras fixas" tem sido efetivamente imposta (ou não) aos indígenas engajados em dinâmicas de regularização fundiária.

\footnotetext{
${ }^{5}$ No sentido proposto por Gray (no prelo), o termo landscape ou "paisagem" trata dos aspectos estéticos constitutivos das relações pessoais de interação com o meio ambiente, explorando a dimensão cognitiva e subjetiva dessa experiência. Sua abordagem entende que o meio ambiente é também criado pela agência humana e que cada indivíduo desenvolve uma relação especial com o território.
} 


\section{Um panorama inicial sobre os Caiapó}

Os Caiapó ou Mebengokré são classificados como um grupo indígena Macro-Jê, compartilhando "traços culturais" com outros povos de língua Jê. Seus parentes mais próximos são os Suyá e os Apinayé e as estimativas glotocronológicas mais confiáveis situam a separação desse grupo ancestral há aproximadamente quatro séculos (Turner, 1992).

Reza a tradição oral caiapó que a "região de campos" - onde hoje está inserida a Terra Indígena Las Casas - teria sido palco dos mitos indígenas, e ali teriam acontecido episódios de fundamental relevância para o pensamento e a organização indígena. Em um desses eventos, Nokorekwe, uma mulher já madura ${ }^{6}$, encontrou um rato às margens do rio Kokati ${ }^{7}$. Ao vê-la por aquelas paisagens, esse animal chamou Nokorekwe prometendo mostrar-lhe um delicioso alimento: o milho. Depois de dar a ela algumas espigas, a mulher voltou à comunidade e compartilhou daquelas sementes com as pessoas de sua aldeia. Para comemorar tal descoberta, os Caiapó cantaram e dançaram. Todavia, depois das festas, um grupo de homens pediu a Nokorekwe que os levasse até o pé de milho, e ela assim o fez. Contudo os homens não conseguiam ter acesso às sementes de milho, pois elas estavam guardadas dentro do estômago do rato que, por sua vez, escondia-se no tronco desse pé de milho, forte e resistente. A duras penas, conseguiam abrir uma fenda, mas tão logo o faziam, a planta se regenerava, e os homens precisavam reiniciar o trabalho. Cansados, voltaram à aldeia e chamaram os membros da comunidade para ajudar nesse processo. Com o esforço coletivo e ativo de todos, os Caiapó conseguiram finalmente derrubar a planta e, assim, passaram a ter acesso ao milho (Lukesch, 1969).

Para Turner (1992), essa narrativa explicaria a facção primeva dos Caiapó, processo que continua acontecendo e marcando fortemente essa sociedade de modo geral. À medida que recolhiam as sementes de milho, passavam também a falar diferentes línguas e subdividir-se em vários subgrupos que, desde então, se deslocam por um vasto território.

Verswijver (2002), que também se detém sobre esses dados, elaborou uma tese segundo a qual o "grupo ancestral" se subdividiu em três grupos principais: os Irã'aMraire ("os que passeiam nas planícies" ou "os que andam sob a claridade da lua"), cujas aldeias localizavam-se nos Rios Arraias, Pau D' Arco e Chicão; os Goroti Kumrem (" os homens do verdadeiro grupo grande"), que se estabeleceram ao norte; e, finalmente, os Porekry ("os ho-

\footnotetext{
${ }^{6}$ Isto é, com mais de quatro filhos e já na menopausa (Vidal, 1977).

${ }^{7}$ O Rio Kokati pode ser o Rio Araguaia ou Tocantins, os dados são controversos sobre o assunto. Particularmente, acredito que se trata do Rio Araguaia, ao menos, foi isto o que os Caiapó de Las Casas me disseram.
} 
mens dos pequenos bambus"), que viviam a noroeste do Rio Pau D'Arco. Atualmente os Goroti Kumrem estariam divididos nos seguintes subgrupos e aldeias: Gorotire (TI Caiapó, aldeias Gorotire, Kikretum e Las Casas ${ }^{8}$ ). Os Gorotire novamente dividiram-se, criando os subgrupos Kubenkrankeng (aldeia homônima) e Mekrãgnoti ("os homens com grandes pinturas vermelhas no rosto"). Estes, por sua vez, fracionaram-se em: Mekrãgnoti (TI Baú, aldeias: Kubenkokre, Kenjam, Pykani) e Metyktirè (que vivem nas aldeias Kremoro [Kapoto], Metyktirè, Piaraçu). Já os Pore-kry dividiram-se em três subgrupos: os Djore (extintos na década de 1930); os Xicrin que vivem atualmente na TI Xicrin do Rio Cateté nas aldeias Pykatingràt e Djudjêkô, cujos nomes querem dizer, respectivamente, "praia", ou "lugar com areia" e "pau d'arco". Um outro grupo xicrin, os Kokorekré, estaria na TI Trincheira Bacajá (Verswijver, 2002; Oliveira Jr., 1995).

Para o leitor deste artigo, a discussão serve apenas para compor um quadro de orientação, pois isto, às vezes, pode ser necessário, sobretudo, porque o grupo de Las Casas é bastante heterogêneo. Aliás, é necessário ter certa cautela ao utilizar tais dados. Afinal, há grande controvérsia em relação a essas subdivisões, já que os autores possuem diferentes pontos de vista sobre o assunto ${ }^{9}$. Além disso, o termo seria impreciso conceitualmente e haveria uma tendência em "essencializar" uma identidade - grupal e territorial - e tratar a constituição de uma aldeia caiapó de modo estático e homogêneo (Oliveira Jr., 1995). O mais comum, contudo, é encontrar aldeias caiapó compostas por indivíduos provenientes de vários subgrupos, cabendo notar que grupos de pessoas se unem e se separam, voltando a se unir e se separar ao longo da história mebengokré tendo em vista as contingências históricas e o desejo ativo de homens e mulheres nesse sentido. Aliás, esta é exatamente a situação encontrada em Las Casas, como pretendo demonstrar.

\footnotetext{
${ }^{8}$ Perceba-se que ele considera que Las Casas é composta unicamente por índios Gorotire, quando na verdade ali vive um grupo bastante heterogêneo.

${ }^{9}$ De acordo com Lea (1986), por exemplo, os Xicrin devem ser considerados como uma sociedade à parte. Ao falar das cisões ela apresenta um modelo que difere, em certos aspectos daquele de Verswijver (2002). Segundo ela, ao final do século XIX, havia um grupo ancestral: Goroti Kumre(notemos que a grafia é diferente da de Verswiver). Este grupo primevo fracionou em: Xicrin e Caiapó Gorotire. Os Xicrin separaram-se em Xicrin do Rio Cateté e do Bacajá. Os Gorotire, por sua vez, subdividiram-se em: Irã'amraire (ou Caiapó Pau D'Arco), extintos ainda nos anos 1940, e Gorotire Caiapó. Estes, continuaram a fracionar-se sucessivamente dando origem aos subgrupos: Kararaó(quase extintos ao final dos anos 1980); Mekrãgnoti(das aldeias Mekrãgnoti e Pukanu); Metùktire (das aldeias Kretire e Jarina); Baú (aldeia Baú); Gorotire (aldeias Gorotire e Kikretum); Kuben-kran-ken (aldeia Kuben-kran-ken); Kokraimoro (aldeia Aùkre) (Verswijver, 2002). Os Xicrin, juntamente como os Kararaó; Mekrãgnoti, Metùktire e Baú teriam suas aldeias localizadas a oeste do Rio Xingu ao passo que os outros subgrupos estão inseridos a leste do Rio Xingu e todos os subgrupos caiapó (a exceção dos Xicrin) comporiam a "comunidade caiapó" (Verswijver, 2002, p. 14, 23). Além de um ponto de vista relativamente distinto, Lea adota uma grafia distinta daquela de Verswijver.
} 


\section{Contextualizando Las Casas e os referenciais teóricos utilizados}

Como afirmei anteriormente, Las Casas é um território de ocupação tradicional Caiapó. A título de introdução, ali vivia o subgrupo irã'a'mraire, extinto no início do século XX devido aos conflitos com regionais e guerras intraétnicas. A região era povoada também pelo subgrupo kubengrankeng. Havia ainda uma cidade em formação, Conceição do Araguaia, na qual havia uma instituição religiosa que abrigava índios caiapó, com o objetivo de convertê-los ao catolicismo e "integrá-los" à sociedade nacional. No contexto, os Xicrin também costumavam deslocar-se por essa localidade, amedrontando a população local que, por sua vez, empreendia verdadeiras "expedições de caça" aos índios, levando, inclusive, à extinção dos Irã' a'Mraire, conforme já apresentei.

Diante das circunstâncias e dos interesses em transformar a região em uma extensa área de criação de gado, foram empreendidos esforços no sentido de "pacificar" os Xicrin, que, na ocasião, eram considerados os mais belicosos. É nessa situação, que remonta à década de 1940, que o órgão indigenista oficial da época, o Serviço de Proteção aos Índios (SPI), fundou o "Posto de Atração Las Casas". Aqui começa a "história oficial" de Las Casas. Aliás, o período compreendido entre as décadas de 1940 a 1960 é de central importância para a compreensão desses eventos. Afinal, é nessa época, que Las Casas, de acordo com os indígenas, teria se transformado em uma "aldeia dos mortos" em virtude de epidemias de sarampo, entre outras, que dizimaram parte da população ali residente. Esse dado, aliás, merece maior atenção.

Ora, entre os grupos indígenas pertencentes ao tronco Macro-Jê, no qual se incluem os Caiapó, é comum "abandonar" aldeias em que existe um contingente muito grande de $\operatorname{mortos}^{10}$. Sobre essa questão, note-se que, de acordo com a cosmovisão caiapó, os mortos continuam a existir, só que seus comportamentos representam a antítese da sociabilidade pretendida. Além de antissociais, os mortos, chamados pelo grupo como mekaron, são potencialmente perigosos, como tratarei adiante. Esse aspecto, somado à política indigenista da época e à pressão de segmentos nacionais pela ocupação da área de Las Casas, acabou provocando o êxodo do grupo para outras terras caiapó no ano de 1965.

É somente trinta anos depois, em meados de1990, que alguns dos Caiapó que viveram na antiga aldeia de Las Casas se organizaram de modo a empreender a "viagem de volta", para usar os termos propostos por Pacheco de Oliveira (2004). Sabiam que as dificuldades seriam inúmeras. Além da necessidade de

\footnotetext{
${ }^{10}$ Para maiores informações ver Carneiro da Cunha (1978), que faz uma análise seminal acerca dessa temática, entre outros autores.
}

Tellus, ano 11, n. 21, jul./dez. 2011 
intensa mobilização política, as terras estavam totalmente ocupadas por segmentos regionais. Por outro lado, a reconstrução desse território exigia uma espécie de dupla "negociação": por um lado, com o "direito ocidental", que define os parâmetros legais de uma "Terra Indígena", fixando suas fronteiras; e por outro, com os próprios mekaron. Isto é, a despeito de questões de ordem política e administrativa, para os Caiapó havia uma dimensão cosmológica importante a ser considerada e, não obstante, não prestigiada ou "imaginada" pelos parâmetros legais vigentes, ancorados na lógica ocidental ${ }^{11}$.

Diga-se de passagem que, à época em que o trabalho de identificação foi realizado, a aldeia Las Casas estava sendo ocupada por uma população de aproximadamente 50 índios, em sua maioria composta por idosos e crianças. Os Caiapó estavam reconstruindo a aldeia e reconfigurando suas redes sociais, fatos que eram bastante convidativos para uma análise mais densa. A receptividade indígena corroborava essa impressão: fui prontamente "adotada"12 pelo grupo, alimentada e, inclusive, "humanizada" ao ter meu corpo pintado ${ }^{13}$.

Cabe ressaltar, de início, que a situação etnográfica encontrada em Las Casas é bastante peculiar. No caso caiapó, as análises têm dado pouca importância aos aspectos subjetivos e, como consequência, as relações entre homens e mulheres, entre natureza e cultura, centro e periferia, têm sido descritas pelo dualismo que as constituem, e as abordagens produzidas têm sido relativamente rígidas quando discutem o estatuto dessas relações. $O$ fato, aliás, me fez sentir certo desconforto, pois os dados de que disponho e a forma através da qual os tenho interpretado não parecem se encaixar inteiramente em nenhum dos modelos precedentes.

Afinal, os índios de Las Casas apontaram, desde o início, para a importância da criatividade, da subjetividade e da criação de relações interpessoais agradáveis. De outro modo, indicaram a necessidade de uma reflexão constante entre estrutura e prática, entre aspirações individuais e coletivas - que devem ser pensadas de modo complementar. Através dessa percepção e de suas próprias práticas sociais, demonstraram que vida em comunidade

${ }^{11}$ Para uma discussão mais densa, ver Berman (2004), que trata da história de formação do sistema jurídico ocidental, demonstrando tratar-se de um sistema cultural que erigiu as bases do que chamamos, em um sentido mais amplo, de "Ocidente".

${ }^{12}$ Certo dia, quando estava em campo, Maria Eugênia, me tomou pelo braço e disse: "Agora você é minha parente. Eu sou sua mãe e as minhas filhas são suas irmãs". A adoção, aliás, é também uma prática bastante comum entre os Caiapó. Embora não se possa dizer muito a respeito da integração das "Casas" matrilaterais, descritas por Lea (1986), é possível notar que, através da "adoção", os índios parecem integrar membros suplementares e ativar laços solidários, como aconteceu comigo naquele contexto específico.

${ }^{13}$ Um dado muito interessante é que, para os Caiapó, um bebê só se transforma em um ser humano no sentido pleno do ser, quando recebe a pintura corporal, que marca de maneira tão forte esse grupo indígena. É por esta razão, entre outras, que um bebê imediatamente ao nascer tem seu corpo recoberto por pinturas corporais. 
se apresenta como um modelo ideal em que as pessoas vivem de maneira solidária em um lugar simbolicamente importante e, não obstante, fértil ${ }^{14}$. Além do conforto afetivo, esse "estilo de vida" teria como valores essenciais a comensalidade e "conviviabilidade", termo que indicaria que a vida social é marcada mais pela ênfase sobre o informal e o íntimo, do que sobre a regra e sua obediência. As relações interpessoais seriam criadas diariamente por intermédio das ações e afetos específicos de cada um de seus membros (cf. Overing, 1999).

Por outro lado, as estruturas que tão bem caracterizariam uma "sociedade caiapó" estavam ausentes em Las Casas. Todos os adultos pareciam estar unidos, a despeito da divisão sexual do trabalho, através do engajamento cotidiano em suas atividades produtivas, sendo que as instituições descritas pela grande maioria dos caiapólogos não eram operantes nesta aldeia Isto é, não havia uma "Casa dos Homens", tal como descrita por Turner (1965), tampouco uma instituição semelhante às "Casas" de Lea (1986).

De outro modo, se o mundo caiapó é marcado por complexas hierarquias sociais (cf. Vidal, 1977), as relações interpessoais em Las Casas parecem ter caráter mais fluido e informal. Os vínculos entre as pessoas provenientes de subgrupos e áreas indígenas diferentes foram também criados ao longo de suas trajetórias de vidas e de acordo com o desejo ativo de indivíduos nesse sentido. Além de uma convivência em comum e da busca por um tipo de sociabilidade ideal, os índios de Las Casas frisaram tentar evitar o surgimento de estados emotivos desagradáveis, desencadeados pela ira, pelo ciúme e disputa por recursos.

Diante do exposto, apresentou-se a seguinte questão: como dialogar com a teoria já existente diante de uma realidade que parece tão diferente dos modelos apresentados pelos etnólogos? Como lidar com a subjetividade indígena, que se apresenta como central nesse cenário, se essa questão é frequentemente ocultada em estudos sobre o grupo?

Voltando às referências bibliográficas, encontrei uma proposta teórica interessante na obra de Giannini (1991), que propõe que os estudos sobre a cosmopraxis indígena são especialmente reveladores quando apontam para a interação entre diferentes domínios, entre prática e pensamento. Assim, o ato de matar um animal ou deslocar-se por domínios que transcendem a aldeia,

\footnotetext{
${ }^{14}$ A vida e os modos de interação entre as pessoas precisam ser agradáveis e a experiência da beleza é outro aspecto valorizado, pois é importante para o estabelecimento de um modo de vida que se apresenta como ideal. Para Fisher (2003), os rituais caiapó visam principalmente produzir sentimentos que afastam a tristeza e trazem para a vida cotidiana a alegria e a harmonia, na medida em que minimizam os conflitos, fazendo também com que as pessoas sintam-se pertencentes a uma comunidade de "parentes". Essas emoções, que são estados sociais experimentados pelos indivíduos, são produzidas principalmente no clímax dos rituais, através da dança, da música, circulação de alimentos e troca de ornamentos cerimoniais.
} 
inclui também um senso moral e estético, e as práticas mais habituais estão associadas a uma série de regras e preceitos que devem ser observados sob pena de afetar a humanidade como um todo. Assim, caberia enfatizar não somente as estruturas duais que constituem a sociedade caiapó (como as relações entre centro/periferia; natureza/cultura, estrutura/prática; homem/ mulheres), mas também observar, mais atentamente, as formas de mediação entre diferentes dimensões e domínios.

Noto, contudo, que Lukesch (1969) já havia adotado uma perspectiva semelhante em seu livro Mito e Vida dos Índios Caiapós, apresentando uma abordagem singular, mas não menos valiosa. Afinal, este autor foi um dos primeiros caiapólogos a demonstrar que as concepções de mundo indígena estão também expressas nas relações sociais e nos modos de interação com a natureza, o cosmos e o próprio espaço. De outro modo, trabalha com um "senso de comunidade" de uma maneira relativamente distinto, valorizando as relações de complementaridade entre as pessoas a despeito das diferenças de gênero e idade. Assim, embora não desconsidere a importância das estruturas formais, propõe que a comunidade é uma noção-chave para entender a realidade e o pensamento caiapó, cabendo ainda estar atento para o papel atribuído à emotividade na definição das práticas sociais indígenas. Indica que as condições objetivas da existência, assim como os estados subjetivos, são aspectos centrais para a configuração de um todo social coerente e dotado de sentido. Todavia, a despeito de sua sensibilidade, seus estudos têm sido pouco utilizados, e sua obra, considerada como secundária.

Mesmo reconhecendo as limitações de Lukesch (1969) em termos de rigor metodológico, as ideias lançadas por ele são centrais para pensar a realidade de Las Casas ${ }^{15}$. Afinal, entre outros aspectos, o que os índios de Las Casas estão evidenciando, de diversos modos, é a importância da subjetividade, dos desejos e da potência transformadora das emoções. E, embora reconheçam a existência das estruturas duais expressas no sistema de metades, na relação entre homens e mulheres, entre vivos e mortos, etc., demonstram que o "senso de comunidade" transcende a essas relações formais.

Por outro lado, a vivência em Las Casas, para onde retornaram em 1996, implicou uma série de "readequações" (quanto à estrutura social) e de "reinterpretações" (quanto à relação entre "vivos" e "mortos", entre homens e mulheres e entre categorias de idade diferenciadas), tornando-se condição para a formação daquele novo "coletivo" caiapó. Apesar dessa configuração

\footnotetext{
${ }^{15}$ Lukesch (1969), por exemplo, sugere que todos os membros adultos de uma aldeia são importantes para a superação de dificuldades que se impõem aos Caiapó em sua existência terrestre, lançando uma nova perspectiva para pensar nas relações de gênero e categorias de idade. Por outro lado, seu ponto de vista parece ser capaz de articular domínios que permanecem separados em inúmeras pesquisas sobre o grupo.
} 
singular, o grupo de Las Casas permite entrever que o "constante" caiapó seria um modo de "construir-se no espaço-território", e é isto que pretendo demonstrar.

Friso, finalmente, que apesar de o trabalho ter sido realizado no início dos anos 2000 e o trabalho de campo ter tido uma série de limitações, Las Casas sempre esteve em meu foco de atenção e, na medida do possível, busquei atualizar informações sobre esse contexto. Dados obtidos em 2011 indicaram que a população da aldeia praticamente triplicou, o que tem gerado diversos problemas de ordem ambiental e social. Apesar de a Terra Indígena estar oficialmente reconhecida e homologada, ainda existem "brancos" ocupando a área, o que gera uma série de conflitos e impede a plena efetivação do modelo de sociabilidade buscado pelo grupo. Assim caberia a realização de novos estudos em Las Casas de modo que pudéssemos avaliar a configuração atual. Desse modo, além dos objetivos acima mencionados, o artigo apresenta-se como uma espécie de convite à pesquisa nesse local, devido à singularidade e à relevância teórica que as questões apresentadas lançam aos etnólogos. Diante desse amplo panorama, passemos agora à história de Las Casas e às interpretações dos Caiapó acerca desse território do processo de reconhecimento oficial de suas terras.

\section{Histórias de ontem: da "pacificação" Xicrin ao processo de reconstrução de Las Casas}

Sudeste do estado do Pará, ano de 1996. Um pequeno grupo de Caiapó deixa a TI Caiapó. O destino é a antiga aldeia Las Casas, onde funcionou um Posto de Atração do SPI nas décadas de 1940 a 1960. Entre eles, estão os índios Parityk, Tapiri e Maria Eugênia, além de Pedro Aybi. Essas pessoas e suas famílias nucleares formam um grupo caiapó bastante heterogêneo, uma vez que pertencem a diversos subgrupos: são Kubenkrankeng, Xicrin, Gorotire e Mekrãgnoti. Não obstante, todos se reconhecem como òmbikwa, termo utilizado para indicar relações de parentesco ${ }^{16} \mathrm{e}$ "companheirismo" designando "pessoas que se que cuidam mutuamente" (Vidal, 1977).

Cabe notar que Parityk, Tapiri e Maria Eugênia foram personagens centrais nesse processo e, por isso, serão destacados. Estabeleceram seus primeiros contatos ainda na década de 1950, quando da "pacificação" dos índios xicrin. Parityk e Tapiri faziam parte da expedição de guerreiros xicrin, ou seja, eram

\footnotetext{
${ }^{16} \mathrm{O}$ "parentesco" aqui é tratado como um sistema capaz de estruturar e reproduzir os grupos sociais, determinando as relações sociais e criando relações que envolvem reciprocidade, dádiva e solidariedade. Além de sua dimensão simbólica e ideológica, o parentesco diz respeito a um sistema de atitudes que ajuda a organizar, através de suas terminologias, o próprio funcionamento da vida social (cf. Lea, 1986).
} 
parte do grupo a quem se pretendia justamente "pacificar". Maria Eugênia, uma Kubenkrankeng órfã criada na Missão Dominicana de Conceição do Araguaia, auxiliava o sertanista Miguel Araújo no processo de pacificação dos índios xicrin, juntamente com seu marido, Paulo Kryt. A pacificação, naquele contexto, ganhou ares de imprescindibilidade, e recursos foram destinados para a efetivação desses objetivos.

No entanto, ao contrário do que se previa, a "pacificação" se estendeu por vários anos. O Posto Las Casas foi fundado na década de 1940, e foi somente em 1952 que Miguel Araújo, auxiliado pelos índios caiapó residentes em Las Casas, particularmente Maria Eugênia, conseguiu estabelecer os primeiros contatos "pacíficos" com um grupo de guerreiros xicrin, dentre os quais estavam Parityk e Tapiri. Na ocasião, o grupo foi levado ao centro da antiga aldeia Las Casas. Maria Eugênia providenciou a comida, prontamente aceita pelo grupo que, posteriormente, cantou e dançou no centro da aldeia, criando, desde então, novas e duradouras redes de sociabilidade.

Uma vez estabelecido o "primeiro contato", as condições de vida em Las Casas foram se deteriorando rapidamente. A falta de recursos, o não reconhecimento daquele território, a pressão por parte da sociedade nacional para ocupar aquela área foram tornando a vida insustentável. Pior seriam as doenças, que se propagaram e levaram muitos à morte. Las Casas, naquele contexto, ficaria marcada pelo conflito, pelo abandono, pela doença e pelo signo da própria morte, interpretada pelos Caiapó, como algo não desejável. Para eles, a morte significa uma espécie de prostração total e desgraça extrema (Lukesch, 1969, p. 203).

Naquelas circunstâncias, de acordo com interpretação indígena, Las Casas passou a ter um contingente grande de mortos, que vagava por aquelas terras, buscando estabelecer contatos com seus parentes. No início dos anos de 1960, com a disseminação das doenças e o aumento da mortandade, o grupo de "vivos" tornava-se menor, ao passo que a "aldeia dos mortos", que se acredita localizada no cume de uma cadeia serrana a qual chamam de Tekrejarôtire, tornava-se mais numerosa, ameaçando a vida de todos.

Note-se que, na perspectiva indígena, os mortos são seres antissociais que buscam a todo custo estabelecer relações com o mundo dos "vivos". Ou seja, parece haver uma busca pela convivialidade, mas os vivos a recusam, porque não querem morrer - quer dizer, não querem conviver com os mortos. O contato com os mortos, que é uma possibilidade para o grupo, é visto como um acontecimento que pode levar à morte e, por isso, é evitado de todas as formas. Os próprios pertences dos mortos, ainda que existam reconfigurações desse padrão na atualidade, são queimados, e os parentes esforçam-se por aplacar a saudade que sentem de seus parentes mortos, temendo uma aproximação, potencialmente perigosa (Vidal, 1977; Lukesch, 
1969). Assim, a morte está associada a uma série de sentimentos que devem ser evitados.

Sobre essa questão, cabe notar que Lukesch (1969), ao analisar os mitos caiapó, revela que as emoções são interpretadas em termos sociais. Parecem representar um tipo de sociabilidade que rejeitam fortemente, pelas consequências que podem gerar. Isto é, os Caiapó percebem o tempo de maneira não linear, acreditando que não há uma ruptura significativa entre a realidade passada e atual. Nesse sentido, os acontecimentos seriam absolutamente reversíveis, e a configuração presente depende da agência humana, no que se refere às suas práticas sociais e ao controle de sentimentos, principalmente daqueles que possuem uma conotação negativa, como a raiva, a ira, o ciúme e a tristeza, entre outros.

Diante dessa perspectiva, há uma preocupação em manter o equilíbrio do cosmos, através da adoção de práticas de apropriação adequada de elementos da natureza. Através de condutas meikumrem ${ }^{17}$ acreditam contribuir para evitar com que um passado caótico - em que as mulheres dormiam com os animais, e os homens não tinham conhecimentos sobre a linguagem cerimonial e viviam amedrontados diante da existência de seres sobrenaturais que os matavam e comiam de sua carne, etc. - volte a ser a condição do presente.

Desse modo, ao contrário dos mortos, os homens e mulheres adultos caiapó, esforçam-se por controlar a potência criadora e transformadora que possuem dentro de si, dominando seus desejos e sentimentos como a paixão, o ciúme, a inveja, a ira e a cobiça em prol da coletividade. Essa condição permitiria a reprodução da "vida em comunidade", em que todos se reconhecem como parentes e "companheiros", uma noção extremamente importante para o grupo $^{18}$ (cf. Vidal, 1977; Lukesch, 1969). Cada família nuclear, por sua vez, funcionaria como uma unidade produtiva elementar e, na medida em que todos trabalham, é possível criar um excedente, produzir "comensalidade" e realizar complexos cerimoniais, marcados por um senso de beleza bastante apurado. Todos esses aspectos satisfazem não somente aos ânimos individuais, mas também fortalecem os vínculos interpessoais e permitem o construir do cotidiano.

A conjuntura encontrada em Las Casas na década de 1960, portanto, apresentava-se como contrária ao que o ideal de vida caiapó pregava. A baixa densidade populacional e o aumento de número de mortos devido às epidemias foram aspectos centrais para que decidissem deixassem Las Casas, o que significava fugir dos mortos, das doenças e de outras ameaças.

\footnotetext{
${ }^{17}$ Esta expressão é bastante utilizada e denota sempre sentimentos e noções que são tidos como agradáveis e positivos.

18 "Os companheiros são aqueles com quem se pode falar livremente, eles não tem vergonha (pyaám) um do outro [...] São como parentes (òmbikwa), porque estão juntos todos os dias, trabalham em conjunto e se divertem em conjunto" (Vidal, 1977, p. 123).
} 
Diante do quadro, o grupo foi se cindindo aos poucos. Migraram conforme os ânimos individuais para outras áreas indígenas ${ }^{19}$. Aos poucos, Las Casas tornou-se vazia, ou de outro modo, ocupada pelos mekaron unicamente. O "Posto de Atração" foi oficialmente dissolvido em 1965, e aquelas terras foram paulatinamente ocupadas por segmentos nacionais diversos.

Parte do grupo de Las Casas se deslocou para a TI Xicrin do Rio Cateté, ao passo que a maioria se destinou para TI Caiapó, lugar para onde foram Maria Eugênia, Parityk e Tapiri. Todavia, ao que tudo indica, a vida nesta TI parece ter sido permeada por problemas, que foram piorando com o passar dos anos e aumento da população local. Ao final de 1990, esta era umas das terras mais populosas e estava bastante degradada ambientalmente. Os recursos, de ordens diversas, tornavam-se mais e mais escassos, aumentando a tensão entre o grupo (Sousa, 2000). O quadro sugere, dessa forma, que os preceitos fundamentais que determinariam uma "boa vida" não estavam sendo assegurados pela prática de interação cotidiana. O grupo de Las Casas, em particular, afirma que não estava conseguindo relacionar-se de forma solidária e não mais se reconhecia como pertencentes a uma comunidade de parentes, em que todos se sentem mutuamente vinculados e responsáveis pela manutenção de boas relações entre si. A ideia de comunidade que conseguiram estabelecer em Las Casas, ainda que por um breve período de tempo, não estava sendo assegurada, principalmente pela disputa por recursos. Os Caiapó de Las Casas inclusive afirmavam que não se sentiam em "casa" na TI Caiapó, sendo preteridos quando tentavam ter acesso aos bens e direitos específicos.

Percebendo essa situação, Maria Eugênia, entre outros, indicou que seria necessário organizar-se coletivamente e retomar as terras do antigo Posto de Atração, sabendo, desde o princípio, que se tratava de um processo complexo. Antevendo as dificuldades, ela assim como Tapiri cogitaram inclusive a ideia de viver no Xingu, onde também possuem parentes. Esse deslocamento ${ }^{20}$, diante das circunstâncias e da falta de apoio concreto para que voltassem para Las Casas, apresentava-se como uma forma para resolver, ainda que não de forma definitiva, um certo desconforto advindo do ambiente de animosidade que reinava na TI Caiapó.

\footnotetext{
${ }^{19}$ Tinham se dirigido para a Terra Indígena Caiapó em várias ocasiões. Alguns deles foram participar de festas cerimoniais, outros foram visitar seus parentes ou fazer tratamento médico, e acabaram se transferindo "definitivamente" para outras terras caiapó.

${ }^{20}$ Diga-se, de passagem, que as migrações interaldeias foram frequentes na vida de Maria Eugênia, Tapiri e Parityk e se apresentavam como maneira de diluir as tensões advindas dessas brigas interpessoais. Além de fazerem parte da própria dinâmica caiapó que combina movimento e sedentarismo, estes são processos importantes para a organização social indígena servindo também para criar uma ampla rede de sociabilidade e intensificam os laços de solidariedade entre os membros de uma comunidade. Para além desse domínio, essas expedições são também significativas em termos históricos (Vidal, 1977; Lea, 1986; Turner, 1991).
} 


\section{A reconstrução do território e o processo de reconhecimento legal da Terra Indígena}

No ano de 1996, os Caiapó provenientes de Las Casas conseguiram reunir as condições necessárias para retornar. Voltaram Parityk, Tapiri e Maria Eugênia, acompanhados por membros de suas famílias extensas e por Pedro Aybi, que na época era o Administrador da Executiva Regional da Funai em Redenção (PA). O fato de ocupar esse cargo o colocava em uma posição de destaque, pois poderia disponibilizar recursos públicos (como carros, por exemplo) para efetivar a retomada de Las Casas.

Chegando em Las Casas, os Caiapó procederam à limpeza do terreno, erigindo algumas habitações ao estilo tradicional e dotando, aos poucos, a aldeia com a infraestrutura que seus habitantes apreciam ${ }^{21}$. Desde então, estão vivendo em uma única aldeia, empreendendo expedições cotidianas de caça, coleta, pesca e de controle territorial, atividades realizadas individual ou coletivamente. Todos, inclusive as crianças, falam a língua indígena e os homens utilizam o português no trato com os regionais. Maria Eugênia era a única mulher bilíngue.

Em 2001, como ressaltei, o grupo estava composto por 50 índios. A maioria era proveniente de três famílias extensas: de Maria Eugênia; de Parityk e Tapiri. Em sua maioria, a população de Las Casas estava composta por mulheres, velhos e crianças. Tratava-se de um grupo bastante heterogêneo, sendo que alguns, já nascidos em Las Casas, passaram a se reconhecer por meio dessa identidade, da qual se orgulhavam. Para o padrão caiapó, tratava-se de uma aldeia pequena, o que tem certas implicações sociológicas. Dificulta, por exemplo, a realização de complexos cerimoniais, que exigem grandes quantidades de alimentos e adornos corporais. Mas, por outro lado, em uma aldeia menor, os laços de solidariedade entre seus membros são fortalecidos. A ideia, contudo, era que parentes de diversas localidades viessem a viver em Las Casas, fato que efetivamente parece ter se concretizado, cabendo analisar as implicações desse fato em momento oportuno.

Diga-se, de passagem, que para os Caiapó uma aldeia deve ser um espaço trabalhado pelo que chamaríamos de "agência humana" e transformado em um campo amplo, limpo e circular. Nesse lugar são construídas as habitações indígenas, voltadas para o centro da aldeia ou pátio cerimonial. Em torno das moradias, devem ser cultivadas pequenas roças e os campos próximos da aldeia são deixados para a coleta. Na zona limítrofe desse domínio propriamente humano, localizam-se os cemitérios, pois é sinal de afeição guardar

\footnotetext{
${ }^{21}$ Além da Escola, de um Posto de Saúde, de uma Caixa de Água, a Administração Executiva Regional da Funai de Redenção preparou uma roça coletiva de arroz e instalou o equipamento de rádio na aldeia.
} 
os mortos por perto. Os cemitérios, aliás, parecem servir para demarcar, em termos simbólicos, a distinção entre os mundos com seres e potencialidades distintas. Isto indica, portanto, que há uma relação de ambiguidade entre vivos e mortos, que marca de um modo geral a cultura caiapó. Isto é, há uma relação ora de proximidade, ora de afastamento dos mortos, fato que depende de contextos específicos e de reinterpretações acerca da própria história.

Ao retornar para Las Casas, os Caiapó tentaram aplicar esse padrão de organização e percepção do espaço. Isto é, construíram sua aldeia em uma área de campo limpo e especialmente trabalhado e dispuseram suas oito casas, no sentido estrito do senso, circularmente. Um pouco mais distante da aldeia, existe um cemitério indígena que foi utilizado pelo grupo antigamente, tendo sido reativado depois que voltaram para a área. A localização das roças, dos campos de coleta e a localização de cursos de água próximos da aldeia foram aspectos considerados, e foi essa conjunção de elementos que transformou a aldeia em "um lugar belo e bom para se viver", segundo me disseram.

Em termos habitacionais, a aldeia compunha-se apenas de um círculo ou kikre, em que se inserem as oito habitações bastante parecidas entre si, com um espaço mais ou menos regular entre cada uma. Idealmente, cada habitação abrigaria uma família extensa uxorilocal, mas atualmente esse padrão começa a ser alterado (cf. Lea, 1986). No início dos anos 2000, as famílias extensas estavam subdivididas em unidades menores, ocupando duas ou mais moradas, geralmente contíguas, e esta era exatamente a situação encontrada em Las Casas.

De acordo com o grupo que vive em Las Casas, todos estavam vinculados à Maria Eugênia que, todavia, é mãe "uterina" somente de duas mulheres: Okrãmryk e Kubytkrã. Os demais se reconhecem vinculados à Maria Eugênia a despeito da ausência de "laços de sangue". Há, portanto, uma noção bastante peculiar sobre os laços de parentesco. A linguagem da consanguinidade ${ }^{22}$, frisada por Lea (1986), não é suficientemente capaz de descrever os vínculos estabelecidos entre aquelas pessoas. E, embora reconheçam a relevância dos "laços uterinos", o "coletivo" de Las Casas se relaciona de diversas formas segundo critérios variados. "Tornar-se parente" faz parte da dinâmica da vida social e é resultado do desejo consciente das pessoas nesse sentido e da convivência em uma mesma aldeia.

Além do domínio social, ou da aldeia propriamente dita, os Caiapó reconhecem também a existência do domínio da "natureza", onde estariam as aldeias dos mortos ou me tyknhõpyká, literalmente a "terra daqueles que estão mortos" (Vidal, 1977). A dos Caiapó de Las Casas estaria no cume de uma

\footnotetext{
${ }^{22}$ De acordo com Lea (1986, p. 36) essa distinção é fundamental. Os "laços uterinos" seriam os mais significativos para os Caiapó, já que deles esperam-se a reciprocidade generalizada. Para uma análise mais densa sobre a questão, confira Lea (1986).
} 
cadeia serrana que eles chamam de Tekrejarôtire. Note-se, contudo, que à diferença da "sociedade dos vivos", as "aldeias dos mortos" têm como características principais a ausência de divisões entre as pessoas, seja por gênero, classes de idade ou sistemas de metade, inexistindo também as tensões ou disputas que tão bem caracterizam as sociedades caiapó ${ }^{23}$. Por essas razões, costuma-se afirmar que a terra dos mortos apresenta-se como a antiestrutura da sociedade dos vivos (Vidal, 1977).

Em relação aos mortos, afirmam que eles se transformam em karon, um termo que tem sido traduzido pela palavra alma ou essência vital (Lukesch, 1969; Fisher, 2003). Todos os animais e certas plantas possuem karon e os Caiapó chamam aos seus mortos de mekaron, como disse anteriormente. Nessa concepção, os mortos permanecem vagando pelos lugares em que estiveram quando pertenciam à "sociedade dos vivos", sendo que sua essência ou karon jamais se extingue. Acredita-se ainda que esses seres representam a alteridade radical, justamente por possuírem sentimentos e emoções exacerbadas. Esta, aliás, seria a principal diferença entre os vivos e os mortos, sobretudo em Las Casas, onde as estruturas formais (como a Casa dos Homens, etc.) estavam igualmente ausentes.

Nesse sentido, os dados indicam que os Caiapó afirmam que há uma espécie de continuidade entre a vida e a morte. Ora, os mortos preservam memórias da vida anterior que indicam quem eram seus parentes e os lugares em que andaram. As etnografias sobre o grupo apontam, aliás, que os mortos costumam voltar principalmente para a "casa" de sua mãe ou para as roças de suas irmãs, podendo ainda voltar para o local em que morreram ou foram enterrados (cf. Vidal, 1977 e Lea, 1986). De outro modo, também constituem suas próprias aldeias, transformadas em territórios especiais da saudade (Lukesch, 1969).

Os mekaron também seriam capazes de sentir emoções propriamente humanas. Contudo, ao contrário dos humanos, não se esforçam por controlar esses sentimentos. Esta, aliás, é uma diferença fundamental entre os vivos e os mortos. Os mortos, ao contrário dos vivos, não se esforçam para controlar esses sentimentos, pelo contrário, são dominados por eles. A saudade e a tristeza ${ }^{24}$, aliás, seriam as emoções às quais estariam mais suscetíveis, já que sentem a ausência de seus parentes, havendo ainda um forte desejo em voltar a viver. Afinal, é somente a vida que proporciona sensações verdadeiras: "tudo o que vem depois da morte é pobre, triste e miserável" (Lukesch, 1969, p. 208). Dessa forma, os mekaron acabam por fornecer uma espécie de contra exemplo

\footnotetext{
${ }^{23} \mathrm{O}$ faccionalismo, por exemplo, é um dado recorrente nos estudos sobre os Caiapó. Oliveira Jr. (1995) e Sousa (2000), por exemplo, dedicam-se especialmente a essa questão.

${ }^{24}$ A morte gera a tristeza, que é a expressão continuada de uma emoção que diz respeito à falta da pessoa.
} 
sobre o que os Caiapó consideram essencial e é exatamente por estarem tão sujeitos a esses estados afetivos que se tornam tão perigosos, podendo trazer a doença e a morte para a comunidade (Lukesch, 1969).

Em Las Casas, especialmente, a relação com os mortos parece bastante próxima e tratar o assunto é bastante instigante. $\mathrm{O}$ tema perpassa a grande maioria das entrevistas e através delas os índios evocam muitos mortos presentes naquele território específico: antigos parentes que morreram depois da pacificação dos Xicrin e também índios caiapó do subgrupo irã'amraire. Há também aqueles que morreram guerreando entre si nessa região. Aliás, foi exatamente esse "estado de guerra" que levou o Governo - também interessado na abertura dessas terras para a colonização nacional - a implantar o Posto de "Atração" Las Casas que, paradoxalmente, contribuiu para aumentar o número de mortes em virtude das epidemias que ali se sucederam. Essa situação, como um todo, provocou o êxodo caiapó. Os Caiapó adotavam, portanto, uma atitude recorrente entre os Jê, como tratou Carneiro da Cunha (1978) em outro contexto.

Como apresentado, esse quadro permaneceu relativamente estático até meados de 1990, época em que conseguem reunir as condições necessárias para reocupar a área, então totalmente invadida por segmentos nacionais. Desde então, um coletivo de Caiapó está vivendo em Las Casas, afirmando que "Las Casas é a mais bela de todas as aldeias". Suas paisagens remetem aos aprendizados míticos, informando de maneira privilegiada sobre fragmentos de suas histórias, seja em nível coletivo, seja individual. É também o local ideal para constituir uma comunidade, já que ali todos estão vinculados por relações de afeto de acordo com os próprios índios. A aldeia tem a forma circular, e moradias foram construídas segundo o estilo tradicionaldo grupo. Ainda que não neguem a existência de conflitos, afirmam que não há discussões interpessoais significativas em Las Casas. Todos esses aspectos, portanto, acabaram por tornar Las Casas em um lugar especialmente importante para o grupo.

Contudo, o que dizer dos mortos? O que fazer com eles, já que se sabe que os mekaron continuam vagando por essas terras, havendo inclusive uma aldeia deles na Serra Tekrejarôtire? Se esta aproximação é tão perigosa, por que voltar?

Responder a essa pergunta não é fácil, menos ainda chegar a uma versão conclusiva a respeito. Descrever suas implicações sociológicas é ainda mais complicado, de forma que aqui me limito a lançar algumas hipóteses a respeito. A impressão inicial que tenho é que só é possível entender essa aproximação entre vivos e mortos na medida em que me debruço sobre o contexto etnográfico e tento entender quem são as pessoas que compõem aquele coletivo, dando origem ao processo de reconstrução desse território. 


\section{O xamã, os velhos e os mortos}

Como vimos, Parityk, Tapiri e Maria Eugênia tiveram um papel importante para que os Caiapó voltassem a ocupar Las Casas. O que há em comum entre eles, além de uma história de vida compartilhada, é o fato de fazerem parte da categoria de idade mebengêt, isto é, são consideradas "pessoas maduras". Todavia, de acordo com a literatura sobre o grupo, os membros dessa categoria de idade não costumam desempenhar uma função importante em termos políticos, estando vinculados, em termos conceituais, ao espaço doméstico (cf. Vidal, 1977). Além da pertença a esse grupo de idade, um fato importante a ser considerado seria presença de um xamã (ouwayangá) entre eles: Parityk.

Como explicar o fato de que, justamente os mebengêt empreenderam essa expedição de retorno para a área, o que significou a sua inserção em uma situação de dupla adversidade? Ora, as terras haviam sido invadidas por criadores de gado e, por outro lado, Las Casas havia se transformado em um lugar dos mortos. Diante do contexto, a pergunta permanece: por que razões voltar? Por que justamente um grupo de mebengêt, no qual se encontra um xamã?

A hipótese que levanto é que só poderia mesmo ser um xamã ${ }^{25}$, acompanhado por um grupo de "velhos", os primeiros a retornar, justamente porque são eles que detêm os conhecimentos sobre o cosmos, os "tempos" e as "histórias antigas". São eles que possuem a sabedoria, a experiência, a força em seus pensamentos, sendo que suas ações podem ter implicações globais ${ }^{26}$. $\mathrm{O}$ xamã particularmente tem a função de mediar a relação com os mortos e outros seres sobrenaturais. Aliás, as práticas xamânicas e cantos rituais foram cruciais para que o grupo voltasse a viver em Las Casas, como pude observar em campo.

Segundo minha interpretação, o retorno para a área precisou ser duplamente negociado. Além da necessidade de se resolver um impasse fundiário e dialogar com agências estatais (como a Funai, por exemplo) e com o próprio direito ocidental, hermético e hierárquico, foi necessário "estabelecer contato", através do xamã, com os próprios mortos. Isto foi fundamental para que fossem criadas as possibilidades para voltar a viver em Las Casas. Para tanto, Parityk precisou "viajar" para o lugar dos mortos, já que ele era o único que possuía essa capacidade. A partir de sua morte simbólica, passou a "ver todas as coisas", adquirindo a capacidade de "trocar de roupa" e assim transitar pelos diferentes domínios cósmicos, como demonstra o trecho que se segue.

\footnotetext{
${ }^{25}$ A discussão sobre xamanismo é extensa e não poderia aprofundá-la nesse momento, por fugir aos objetivos propostos do artigo. Para uma visão mais densa a respeito, confira, por exemplo, Viveiros de Castro (1996) e Lima (2008), entre outros.
}

${ }^{26}$ A esse respeito, confira Lukesch (1969).

Tellus, ano 11, n. 21, jul./dez. 2011 
Eu estava caçando anta com outro índio. Eu fui pegar castanha e caçar. Eu vi quatro queixadas. Eu estava atrás do outro índio e fui baleado com um 38. Eu fiquei mal. Eu estava muito mal. Eu fui em Redenção e vi o médico. Eu estou morrendo. Eu estou fumando, fumando... Eu estou tremendo, tremendo... Eu morri.

A minha esposa chorou. O meu filho viu que eu morri. Eu morri. Depois outro velho chegou e disse: “Vamos botar um cobertor nele!”. Aí botaram.

Eu fui lá para baixo, entrei lá no fundo da terra. Só o pajé vai no fundo da terra quando morre. Eu afundei. Eu fiquei lá umas 8 ou 9 horas. Eu estava lá no fundo. Eu fiquei lá. Tem três pajés velhos lá. Tem muito pajé ali, um bocado morreu.

Eu vi muitos índios. Tem uma aldeia como essa lá. Lá embaixo também tem índio. Tem também um rio grande e parente com gasolina. Não sei se tem caça e peixe por que eu não vi. Depois juntaram dois pajés. Eu tava aí e eles se juntaram.

Aí eu subi de novo. Na aldeia tava todo mundo chorando, chorando. Eu morri, mas depois caí de novo. Eu estava na cama. Eu voltei de novo. O pessoal ficou gritando "Ele não morreu!". Aí eu levantei. A minha esposa começou a me abanar. Eu estava suado. Depois disso eu passei a ver todas as coisas.

Em Las Casas tem uma aldeia dos mortos lá na serra mais alta. Eu vi só mekaron mesmo. É uma aldeia bem grande. Lá em Gorotire tem também uma serra com três aldeias dos mortos. De noite eu sempre vou lá. Eu vou até lá. Vou sonhando e quando vejo eu tô lá em cima. Eu tô fumando e eu fui para lá. Eu cheguei lá. O pajé anda por todas as aldeias. Lá tem gaviãogrande, tem muito gavião lá. Os caiapós que estão lá são iguais a nós. Tudo pintado como nós, ornamentados como nós. Só que lá não tem mulher, só homem mesmo. (Parityk, Las Casas, janeiro de 2002).

Parityk, como evidenciei, venceu a doença e a própria morte através da transformação de seu corpo e de suas capacidades, já que passou a poder viajar por diferentes domínios do cosmos, podendo ainda interagir com seres sobrenaturais. Depois dessa alteração sensorial e corporal, tornou-se a pessoa responsável pela articulação entre esses diferentes lugares e habitantes que compõem a geografia universal, detendo para si a responsabilidade em ordenar o caráter desse jogo interacional através de suas práticas e ensinamentos. Esses conhecimentos são expressos nos mitos e nas canções que, além de ensinamentos práticos, possuem aspectos morais que, guiam, por exemplo, os modos ideais de interação entre as pessoas e seres da natureza.

Pode-se dizer inclusive que a proposta de limites territoriais de Las Casas foi fortemente determinada pelos conhecimentos de Parityk, que são socialmente inscritos e simbolicamente interpretados. Parityk tomou para si a 
responsabilidade de criar o processo de diálogo com o próprio GT da FUNAI, bem como foi responsável pela aproximação com os próprios mortos e, para tanto, precisou reinterpretar o caráter dessa relação. Ao fazê-lo, gerou uma nova maneira de se contar a história, criando novas visões de mundo à luz de novos contextos e acontecimentos.

Afinal, se antes Las Casas foi abandonada justamente pela presença dos mortos, para o xamã da aldeia, Parityk, que, reitere-se, coordenou todo o processo de identificação da Terra Indígena, o retorno para Las Casas ganhou importância justamente pelos mortos, pelos vários mortos que Las Casas abriga e cujas essências permanecem. Ou seja, se antes os mortos eram vistos apenas como potencialmente perigosos, na atualidade, mais perigoso seria "abandoná-los", deixar que suas "aldeias" fossem destruídas e transformadas em pastagens, o que significava também perder a própria memória. Isto é, de modo geral, os mortos parecem ter sido transformados em uma espécie de aliados dos índios, quando se tornaram símbolos de resistência na luta pelo reconhecimento oficial de seu território.

Além da importância do xamã, que estabeleceu a mediação com os próprios, a equipe do GT e com os mortos, Parityk assegurou duplamente a possibilidade de um retorno para Las Casas. Tapirie Maria Eugênia, da categoria de idade mebengêt, também foram fundamentais nesse processo. Afinal, como mebengêt,são eles que têm legitimidade para discorrer sobre os acontecimentos decisivos e as proezas de projeção global, determinantes para a ordem vigente ${ }^{27}$. O tema central dessas histórias seria a ideia da transformação: de homens em animais, de homens em divindades e em karon (Lukesch, 1969 , p. 4). No caso de Las Casas, a transformação parece ter sido também de outra ordem: transformar os mortos em aliados dos Caiapó na luta pelo reconhecimento de suas terras. Esse discurso se apresentou de modo bastante enfático quando realizava os estudos de identificação e delimitação da Terra Indígena. Cabe, aliás, deter-me um pouco mais nesse ponto.

Como coordenadora do GT de identificação e delimitação, os Caiapó de Las Casas me perceberam como uma representante do Estado Nacional que poderia contribuir, ou não, decisivamente para o reconhecimento de suas terras. De outro modo, manejavam, ainda que parcialmente, um discurso politicamente orientado para que tivessem suas terras reconhecidas e sabiam

\footnotetext{
27 "Mesmo que a referência a tempos antigos, inclusive os relativos a fatos históricos, nada revele a respeito da efetiva distância no tempo, justamente tal distância no tempo parece valer a favor da validez de uma nova ordem, então iniciada. Os tempos antigos são palco de proezas universais, decisivas para a mentalidade indígena" (Lukesch, 1969, p. 3). O "passado mítico", portanto, é percebido de uma maneira mais dinâmica, e os ensinamentos dos quais tratam são recolocados na ordem do dia e ajudam a produzir reflexões sobre o contexto atual. Há, contudo, um movimento constante entre o passado e o presente, entre mito e história de modo que estas duas realidades parecem se fundir e complementar.
}

Tellus, ano 11, n. 21, jul./dez. 2011 
da importância de cemitérios e lugares sagrados para a legislação indigenista. Contudo, se esses aspectos precisam ser considerados, seria um reducionismo limitar a questão a esse prisma. Ao realizar os estudos de campo, a relação com os mortos sempre foi assunto delicado, sendo que praticamente toda a coordenação dos trabalhos de campo ficou a cargo do xamã, e esse papel e sua visão de mundo apresentaram-se de forma mais enfática em suas práticas sociais do que em narrativas propriamente ditas.

\section{Algumas considerações finais}

Ao retratar parte do processo de identificação e delimitação da Terra indígena Las Casas e falar do fluxo da vida cotidiana e de histórias vividas em um "lugar" especialmente importante (em termos sociais, simbólicos e afetivos), tentei discutir assuntos de alguma relevância para a etnologia indígena e apontar para a importância de algumas noções que têm sido pouco trabalhadas junto aos Caiapó (como a questão dos sentimentos, por exemplo) e em artigos que tratam dos processos de reconhecimento de terras indígenas no Brasil (como interpretam esse processo e a ele incorporam novas concepções e agências).

Ainda que não tenha produzido uma reflexão mais densa sobre o campo da "antropologia das emoções", o intuito foi mostrar como a questão relativa à "produção dos sentimentos" é importante para o grupo e para a definição de um estilo de vida que lhes é particular, como ressaltou Fisher (2003). Mostrei ainda que a reconstrução desse território implicou uma série de "readequações" e "reinterpretações" quanto a aspectos centrais de sua organização social tal como descrita na Etnologia sobre o grupo. Isso, contudo, não implica uma negação dos modelos teóricos propostos para os Caiapó. Ao contrário. Foi a singularidade do contexto encontrado que me levou a adotar caminhos diferenciados.

Um aspecto de central importância foi a reavaliação da relação estabelecida com os próprios mortos que, ao contrário da lógica ocidental, da qual a visão jurídica é tributária, são aqui dotados de intencionalidade e agência. Afinal, ao contrário do que considera a cosmologia ocidental, para os Caiapó, a morte não representa um "fim". Para eles, os mortos ou mekaron continuam existindo, "vagando" pelas terras em que viveram. Nesse eterno caminhar, os mortos preferem especialmente os lugares de roça, onde sabem que encontrarão seus parentes. Aliás, é por essa razão e por reconhecer a presença dos mortos entre os vivos que as mulheres, nas roças, costumam, por exemplo, cuspir em torno de si, pois essa ação os afastaria.

Por outro lado, os mekaron têm suas próprias aldeias. Mas, diferentemente dos humanos, prevalece outro tipo de sociabilidade ou, antes, de 
antissociabilidade, advinda do fato de não controlarem suas emoções. Os mortos, ao contrário dos vivos, seriam dominados pela saudade, inveja, raiva, ciúme e ressentimento, justamente por estarem mortos, por estarem vivenciando o que consideram o mais lastimável de todos os estados do ser. Dominados por essas emoções, que os vivos buscam justamente evitar, podem trazer a doença, provocar novas mortes, bem como desencadear eventos de outros tempos, nos quais os Caiapó eram pequenos e devorados por seres gigantescos (cf. Lukesch, 1969). Assim sendo, os mortos parecem ser dotados de agência e intencionalidade, aspecto duplamente reforçado em Las Casas. Afinal, mesmo sabendo que o discurso em torno dos cemitérios é valorizado pela legislação que trata do reconhecimento de Terras Indígenas no Brasil ${ }^{28}$, reconheceram também que foram os mekaron que os fizeram voltar para Las Casas, por representarem, enfim, parte da própria memória daquele grupo.

Diante do exposto, penso que é preciso reavaliar algumas de nossas concepções acerca dos modos de relação entre as populações indígenas e segmentos da sociedade nacional, especialmente no que concerne à aplicação de políticas públicas voltadas, por exemplo, para os processos de reconhecimento de suas terras. Ao enfatizarmos aspectos políticos - e o próprio potencial do conflito desse processo e das relações daí advindas - penso que frequentemente não temos percebido a grande variabilidade de estratégias que as populações indígenas possuem para criar suas redes de sociabilidade e constituir seu próprio território e percebê-lo de acordo com seus próprios padrões culturais, a despeito de estarem lidando também com discursos e poderes constituídos pelo "outro", no caso pelo direito ocidental. Contudo, mais do que submetidos à lógica ocidental, os índios constituem formas e visões particulares acerca das dinâmicas de interação com práticas e poderes do "Estado Nacional" como tentei demonstrar.

Ao reconstituir parte das histórias de Las Casas, por fim, tentei mostrar que esse coletivo expressa as diferentes formas de perceber esse território concreto e demonstra como esses significados vão sendo alterados de acordo com os contextos e também de acordo com a agência e a subjetividade indígena. Durante esse processo de viver, pensar e agir no território produzem uma representação particular de si e da própria história. Ao contrário de conter-se em uma perspectiva reducionista - criada por instrumentos e políticas públicas voltadas para o reconhecimento de suas terras - parecem ampliar esse olhar, dotando-o de dinamicidade e de significação cosmológica própria.

${ }^{28}$ Confira o Decreto $1775 / 96$ e Portaria 14/96, disponível no sítio da FUNAI.

Tellus, ano 11, n. 21, jul./dez. 2011 


\section{Referências}

BERMAN, Harold. Direito e revolução. A formação da tradição jurídica ocidental. São Leopoldo: Editora Unisinos, 2004.

BRASIL. Constituição da República Federativa do Brasil. Distrito Federal: Senado, 1988.

CARNEIRO DA CUNHA, Manuela. Os mortos e os outros: uma análise do sistema fundiário e da noção de pessoa entre os índios Krahó. São Paulo: Hucitec, 1978.

DI MÉO, Guy. Géographie Sociale et territoires. Paris: Nathan Université, 2001.

FISHER, William H. Name Rituals And Acts Of Feeling Among The Kayapó (Mebengokre). The journal of the Royal Anthropological Institute, v. 9, n. 1, p. 117-135, 2003.

GIANNINI, Isabelle Vidal. A ave resgatada: "a impossibilidade da leveza do ser". 1991. Dissertação (Mestrado em Antropologia Social) - PPGAS/USP, São Paulo, 1991.

GRAY, Andrew. Indigenous Peoples and their Territories. In: OLIVEIRA Jr. ; Adolfo Neves. Decolonising Indigenous Rights (no prelo).

GOW, Peter. Of Mixed Blood: kinship and history in Peruvian Amazon. Oxford: Clarendon Press Oxford, 1991.

GORDON, César. Economia selvagem: ritual e mercadoria entre os índios XikrinMebêngôkre. São Paulo: ISA/NUTI/UNESP, 2006.

KANT DE LIMA, Roberto. Por uma antropologia do Direito no Brasil. Ensaios de Antropologia e de Direito. Acesso a Justiça e Processos Institucionais de Administração de Conflitos e Produção da Verdade Jurídica em uma perspectiva comparada. Rio de Janeiro: Lúmen Iuris, 2008.

LEA, Vanessa. Nomes e nekrets Kayapó: uma concepção de riqueza. 1986. Tese (Doutorado em Antropologia Social) - PPGAS/Museu Nacional, Universidade Federal do Rio de Janeiro, Rio de Janeiro, 1986.

LIMA, Tânia Stolze. Uma história do dois, do uno e do terceiro. In: CAIXETA DE QUEIROZ, Rubem; NOBRE, Renarde F. (Orgs.). Lévi-Strauss. Leituras brasileiras. Belo Horizonte: Editora UFMG, 2008.

LUKESCH, Anton. Mito e vida dos índios Caiapós. São Paulo: Pioneira, 1969.

MELO, Juliana G. A reinvenção da sociedade: Cotidiano e Território entre os Mebengokré (Caiapó) de Las Casas. 2004. Dissertação (Mestrado em Antropologia Social) - PPGAS/Universidade Federal de Santa Catarina, Florianópolis, 2004.

. Relatório Circunstanciado de Identificação e Delimitação da Terra Indígena Las Casas. Brasília: Funai/PPTAL, 2002.

OLIVEIRA Jr., Adolfo Neves. O faccionalismo caiapó: um exercício de interpretação antropológico. 1995. Dissertação (Mestrado em Antropologia Social) - DAN/UND, Brasília, 1995.

OVERING, Joanna. Elogio do cotidiano: a confiança e a arte da vida social em uma comunidade amazônica. Mana, v. 5, n. 1, p. 81-107, 1999. 
OVERING, Joanna; PASSES, Alan. The anthropology of love and anger: the aesthetics of conviviality in Native Amazonia. Londres: Routledge, 2000.

PACHECO DE OLIVEIRA, João (Org.). A viagem da volta: etnicidade, política e reelaboração cultural no nordeste indígena. 2 ed. Rio de Janeiro: Contra Capa /LACED, 2004.

SANTOS GRANERO, Fernando. Writing History into landscape: space, myth and ritual in contemporany Amazonia. American Ethnologist, v. 25, n. 2, p. 128-148, 1998.

SOUSA, Cássio Noronha Iglez. Vantagens, vícios e desafios. Os Kayapó Gorotire em tempos de desenvolvimento. 2000. Dissertação (Mestrado em Antropologia Social) PPGAS/Universidade de São Paulo, São Paulo, 2000.

TISCORNIA, Sofia. Antropologia política e jurídica: problemas de investigação e intervenção em perspectiva comparada. In: KANT DE LIMA, Roberto; EILBAUM, Lucía; PIRES, Lênin (Orgs.). Burocracias, direitos e conflitos. Pesquisas comparadas em antropologia do direito. Rio de Janeiro: Garamond, 2011.

TURNER, Terence. The Social Structure of the Northern Kayapo. 1965. Tese (Dissertação de PHD) - Havard University, Cambridge, 1965.

. Os Mebengokre Kayapó: história e mudança social. De comunidades autônomas para a coexistência interétnica. In: CARNEIRO DA CUNHA, Manuela (Org.). História dos índios do Brasil. São Paulo: Schawarcz, 1992.

VIDAL, Lux. Morte e vida de sociedade indígena Brasileira: os Kayapó-Xikrin do Rio Caeté. São Paulo: HUCITEC, 1977.

VIVEIROS DE CASTRO, Eduardo. Os pronomes cosmológicos e o perspectivismo ameríndio. Mana, v. 2, n. 2, p. 115-144, 1996.

VERSWIJVER, Gustaaf. Enquête Ethnograpique chez les kaiapo-mekragnoti. Paris: École des Hautes Études en Sciences Sociales, 1978.

. Verbete Kayapó. Enciclópedia dos Povos Indígenas. Instituto Socioambiental. Sao Paulo, 2002. Disponível em: <http:// pib.socioambiental.org/pt/povo/kayapo/ print>.

Recebido em 25 de julho de 2011

Aprovado para publicação em 27 de agosto de 2011 
